\title{
Problemática de la contaminacion de plomo ocupacional en los laboratorios de ensayos al fuego de minerales auríferos
}

\author{
Problem of pollution of occupational lead in the laboratories of fire assay of \\ gold minerals
}

\author{
Victor Hugo Peragallo Barrios ${ }^{1}$ \\ Recibido: Junio 2019 - Aprobado: Julio 2019
}

\begin{abstract}
RESUMEN
La contaminación ocupacional de plomo en Perú es un problema grave que hasta el presente no ha sido adecuadamente regulado en el Perú. Las principales actividades que generan contaminación ocupacional de dicho metal abarcan procesos como fabricación de baterías (Ramírez, 2008), fundición de chatarra de plomo, ensayos al fuego para cuantificar oro y plata en la minería. El objetivo de este artículo es identificar las estrategias que deben considerar en la contaminación por plomo en los laboratorios de ensayos al fuego en la determinación analítica de oro y plata, y analizar sus deficiencias (Mérida, 2013). Los datos sobre la contaminación por plomo en los laboratorios de pruebas de ensayos al fuego en Perú son difíciles de encontrar en la literatura disponible.
\end{abstract}

Palabras clave: Regulación; contaminación plomo; plomo en laboratorio; ensayos al fuego; minerales auríferos.

\section{ABSTRACT}

Occupational lead contamination in Peru is a serious problem that has not been adequately regulated in Peru to date. The main activities that generate occupational contamination of this metal include processes such as battery manufacturing, lead scrap smelting, fire testing to quantify gold and silver in mining, etc. The Objective of this article is to identify the details that should be considered in the Lead contamination in fire assay laboratories in the analytical determination of gold and silver, and analyze their deficiencies. Data on lead contamination in fire test laboratories in Peru are difficult to find in the literature available.

Keywords: Regulation; lead contamination; lead in the laboratory; fire tests; gold minerals.

\footnotetext{
1 Licenciado Químico. Alumno Posgrado de Facultad de Ingeniería Geológica, Minera, Metalúrgica y Geográfica, Universidad Nacional Mayor de San Marcos. E-mail: birnehahn@yahoo.com
} 


\section{INTRODUCCIÓN}

La contaminación por plomo en los trabajadores de ensayos al fuego para la determinación de oro y plata, es un grave problema de salud ocupacional por la contaminación por plomo debido al litargirio ( $\mathrm{PbO}$ ) usado en los ensayos produce humos metálicos muy tóxicos de plomo (Martí, 1984), y en la mayoría de los casos los dueños de los laboratorios no les interesa de cuantificar el contenido de plomo en el ambiente de trabajo y menos el contenido de plomo en sus trabajadores (normalmente en sangre) para evitarse problemas laborales con la ley (Acaro, 2014).

La contaminación de plomo ocurre debido las condiciones de la reacción:

1. Reducción del litargirio a plomo $\mathrm{PbO}$ sólido ---$->\mathrm{Pb}$ sólido

2. Temperaturas altas $\left(1000^{\circ} \mathrm{C}\right) \mathrm{Pb}$ sólido ----> $\mathrm{Pb}$ gas

Toda la reacción se realiza dentro de un horno donde se realiza la fundición y copelación

Se trabaja horno cerrado, y para evitar acumulación de plomo en el interior del horno y emitir menor cantidad de plomo por las aberturas de la puerta se le conecta una salida al medio ambiente externo del lugar de trabajo conectado a un extractor.

Existen dos causas de la contaminación: Abertura de la puerta y fugas del horno.

La Figura 1 muestra un horno de puerta de abertura horizontal hacia la derecha.

El gas plomo emitido de la reacción la mayor parte se va al ambiente externo y parte se emite al área de trabajo ya sea por las puertas del horno (no hay cierre hermético) y por posible fugas del horno.
Datos sobre la contaminación de plomo en los laboratorios de ensayos al fuego en el Perú son difíciles de encontrar en la bibliografía disponible en el Perú (British Columbia, 2016).

Datos publicados en el extranjero podemos mencionar el publicado por el editor Dawn Tahrr APPL OCCUP ENVIRON .HYG 6 (4) April 1991 sobre los resultados de medición de varios investigadores sobre el contenido de plomo en el aire en la sala de ensayos al fuego de oro y plata en EEUU en seis laboratorios de ensayos al fuego, encontrándose en 11 muestras promedios entre 110 a 850 $\mu \mathrm{g} / \mathrm{m} 3$ para el TWA de 8 horas, muy superior al valor límite de $50 \mu \mathrm{g} / \mathrm{m} 3$ aceptado en dicho país. Mediciones en áreas adyacentes dio valores entre $10-220 \mu \mathrm{g} / \mathrm{m} 3$ para TWA de 8 horas.

En el trabajo titulado "Niveles elevados de plomo en sangre entre los trabajadores de ensayos al fuego y sus niños en Alaska, 2010-2011", realizado por Porter et al. (2015), el Niño A, de menos de 5 años de edad, tenía BLL (Blood lead level) de 26,7 $\mu \mathrm{g} / \mathrm{dL}$ y era hijo de un empleado que había sido retirado del laboratorio de ensayos al fuego debido a un BLL elevado.

El plomo se produce debido a que se usa grandes cantidades de Litargirio en la fundición inicial y debido a las condiciones de la reacción (altas temperaturas próximas a $1000^{\circ} \mathrm{C}$ y las condiciones reductoras de la reacción se genera mucho plomo según $\mathrm{PbO}$----- $>\mathrm{Pb}$

Cada régulo obtenido en la fundición pesa entre 30-40 g.

El plomo inorgánico entra más comúnmente en el cuerpo a través de la ingestión o la inhalación. Las partículas inhaladas más pequeñas que alcanzan el tracto respiratorio inferior pueden ser completamente absorbidas por el cuerpo. Las partículas de plomo inhaladas más grandes se adhieren a la capa mucosa en las fibras parecidas al cabello llamadas cilios en las vías respiratorias

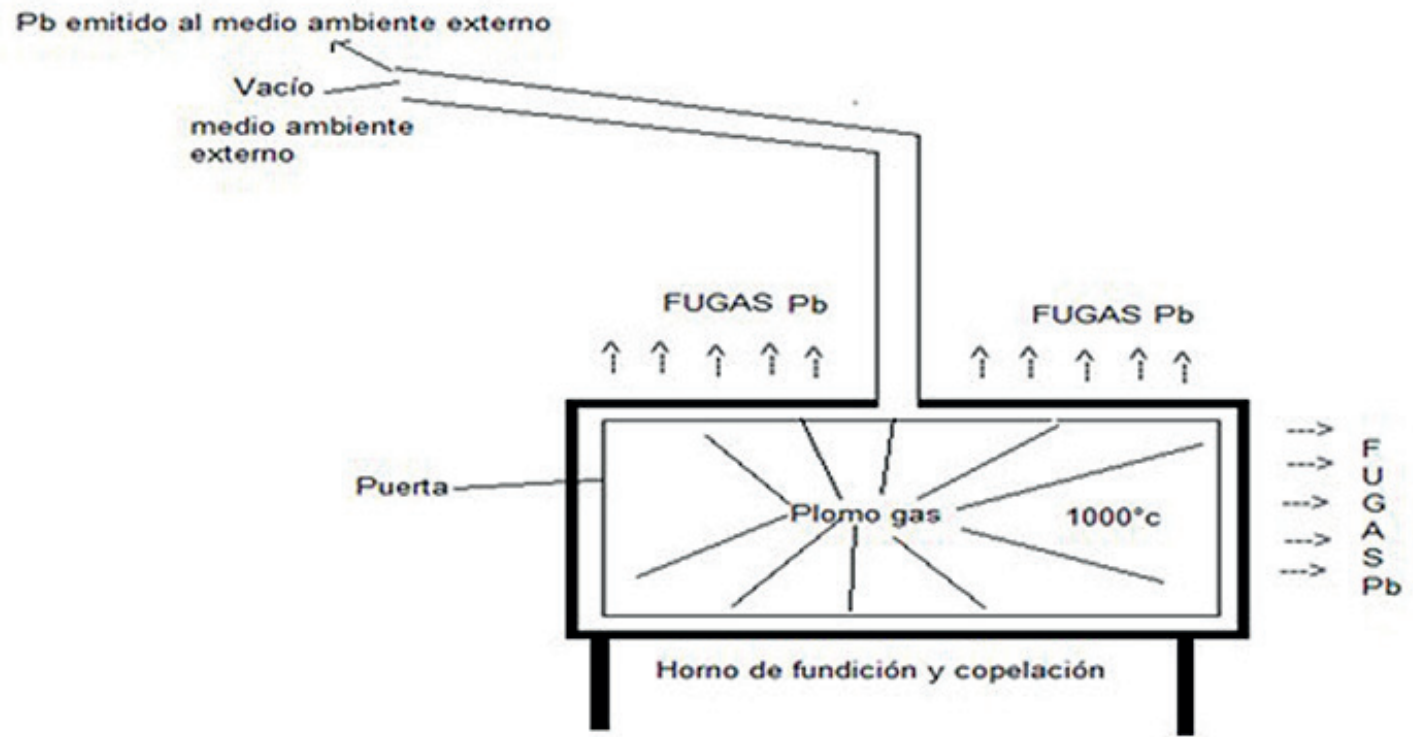

Figura 1. Horno con puerta horizontal 
superiores. La ingestión también puede ocurrir debido al lavado inadecuado de las manos y la cara antes de comer, beber o fumar. Las concentraciones nocivas de plomo no siempre son visibles; y ninguna cantidad de acumulación de plomo en el cuerpo se considera segura.

Una vez que el plomo entre en el cuerpo, viaja por el torrente sanguíneo y se almacena en los huesos y el hígado, los riñones, el páncreas y los pulmones. El plomo imita los iones de calcio, resultando en aproximadamente el 94\% de la cantidad total de plomo que entra en el cuerpo adulto para ser almacenado en los huesos. La semivida de eliminación de plomo en los huesos es de aproximadamente 27 años (ATSDR, 2007) (Whelan, 1997).

Nos parece que para de minimizar la contaminación de plomo en estos casos se debe regular sobre la condición del horno (que tengan fugas mínimas), un sistema de ventilación adecuado ; uso de algún equipo diseñado para capturar con eficacia el plomo emitido en las fugas de plomo ya sea con uno o dos sistemas de extracción (campanas): una interna y otra externa, y ser de carácter obligatorio de usarse tanto en la copelación como en la fundición; limpieza en el lugar de trabajo, normas de trabajo, y finalmente seleccionar respiradores adecuados para evitar la contaminación ocupacional de plomo (Dawn Tharr, 1991).

La contaminación por plomo en el laboratorio se debe analizar bajo dos perspectivas a saber:

a. Plomo en el aire del lugar de los ensayos (plomo ocupacional) el cual será tratado en este artículo.

b. Contenido de plomo en los trabajadores: Plomo en sangre, plomo en orina, huesos, en el cabello entre otros.

El aspecto más importante es el plomo que se respira en el aire, pues si el contenido es mínimo o nulo, el contenido de plomo en el trabajador por contaminación laboral sería mínima o nula.

Habiendo definido procedimientos de trabajo de orden y limpieza, los cuales se puede encontrar bibliografía en otros países y son también procedimientos recomendados por sentido común como por ejemplo no comer en el área de fundición y copelación.

El problema principal de la contaminación sobre los trabajadores del aire de trabajo, se debe regular desde tres puntos de vistas importantes:

1. Uso de sistema de ventilación con los equipos usados en el trabajo con sustancias que contienen plomo y con condiciones que minimicen la contaminación ocupacional del plomo (cuantificar fugas de emisión de plomo y/o usar aparatos o equipos que capturen el plomo emitido por las fugas especialmente de la puerta del horno).

2. Procedimientos de muestreo de plomo con detalles que garanticen resultados fidedignos para ser usados en la evaluación del contenido de plomo emitidos en el ambiente de trabajo. Con respecto al muestreo de plomo ocupacional en el ambiente de trabajo hay límites máximos permisibles para jornadas de trabajo para 8 horas, y no hay límite definidos para jornadas menores a 8 horas en el Perú.

3. Proponer el carácter obligatorio los ensayos de fijación de los cartuchos respiradores para los trabajadores, los cuales no se realizan en el Perú (Coffey, 2004).

\section{METODOS}

Se ha hecho un trabajo de investigación respecto a la contaminación de plomo en los ensayos al fuego para la determinación de oro y plata, algunos datos fueron obtenidos experimentalmente para evaluar el contenido de plomo del ambiente de trabajo en los ensayos al fuego en el proceso de fundición y copelación.

\subsection{Materiales}

\subsubsection{Muestreo}

Adaptación de la Norma NTP 110 Española:

- 3 soportes universales: 3 rotámetros de aire 1-5 LPM Cole Parmer - dos bombas para pescera de 2 - 4 LPM. Llaves de paso de una salida.

- Una caja de filtros de acetato de celulosa de 100 filtros, $37 \mathrm{~mm}, 0.8 \mu \mathrm{m}$.

- $\quad$ Estante de dos cuerpos de metal-pinzas con nuez. pinzas de plástico para los filtros.

- 100 porta filtros de tres cuerpos.

- Mangueras látex o silicona diámetro interno 0.5 cm (se usa para el vacío y para unir el porta filtro con el rotámetro) - cinta teflón o gutapercha para ajustar uniones de mangueras de muestreo.

Calibrador secundario con certificado de calibración (BGI Instruments 890 Tetracal) para hallar curva de calibración de la lectura experimental del rotámetro versus lectura del calibrador. Se muestrea los más cerca posible al horno de fundición y copelación.

\subsubsection{Ataque de las muestras}

- Plancha eléctrica temperatura $80-120^{\circ} \mathrm{C}-12$ vasos de $50 \mathrm{ml}-12$ fiolas de $10 \mathrm{ml}$.

- Dispensador de $\mathrm{HNO}_{3}$

2.1.3 Lectura de muestras: equipo de absorción atómica Variant AA240 y accesorios

Procedimiento de realización de los ensayos.

Premuestreo del lugar de realización del ensayo para planificar las tomas de muestras. 
Protocolo de lavado del material de vidrio instrumental que garantize blancos limpios para asegurar resultados confíables. (Figura 2)

\subsubsection{Calibración de los medidores de flujo: Rotámetro}

\subsubsection{Diseño del muestreo (Figura 3).}

- Se coloca el soporte del filtro en el porta filtro, luego el filtro y se tapa el porta filtro, se anota el código del punto de muestreo.

- Armar el estante a la altura requerida del horno. Colocar los soportes de metal a una distancia de $5-10 \mathrm{~cm}$ de la puerta del horno.

- Colocar el rotámetro en posición vertical sujetándolo con una pinza con nuez en los soportes. Si el rotámetro no tiene llave de control de flujo colocar en las mangueras llaves de paso de control de flujo.

- Conectar la manguera de unión a la bomba tipo pescera y el otro lado al rotámetro por la parte superior, luego colocar el porta filtro que incluye al filtro a la otra salida del rotámetro (por seguridad se puede incorporar un alambre de soporte para que el porta filtro no se caiga al suelo).

- Encender la bomba tipo pescera, llevar a flujo de 2 LPM.

Para el muestreo del suelo de las áreas de trabajo, puesto que se necesita el peso del sólido, muestreamos con el mismo equipo de muestreo; sin rotámetro añadiendo un tubo de vidrio delgado con una salida en punta hacia el suelo y la otra salida al porta filtro.

Se muestrea colocando el filtro: Para el suelo usa solo dos cuerpos en vez de tres cuerpos que se hace para gas. Se coloca el porta filtro por el lado del filtro con ranuras ver Figura 4.

\subsection{Ataque y preparación de muestras}

Se atacan los filtros en vasos de $50 \mathrm{ml}$ con 1-2 $\mathrm{ml}$ de HNO3 concentrado a $80^{\circ} \mathrm{C}$ hasta casi sequedad (pastoso), luego se añade $2 \mathrm{ml}$ de agua y $1 \mathrm{ml}$ de $\mathrm{HNO} 3$ concentrado, se calienta ligeramente a $80^{\circ} \mathrm{C}$ y se trasvasa la solución a

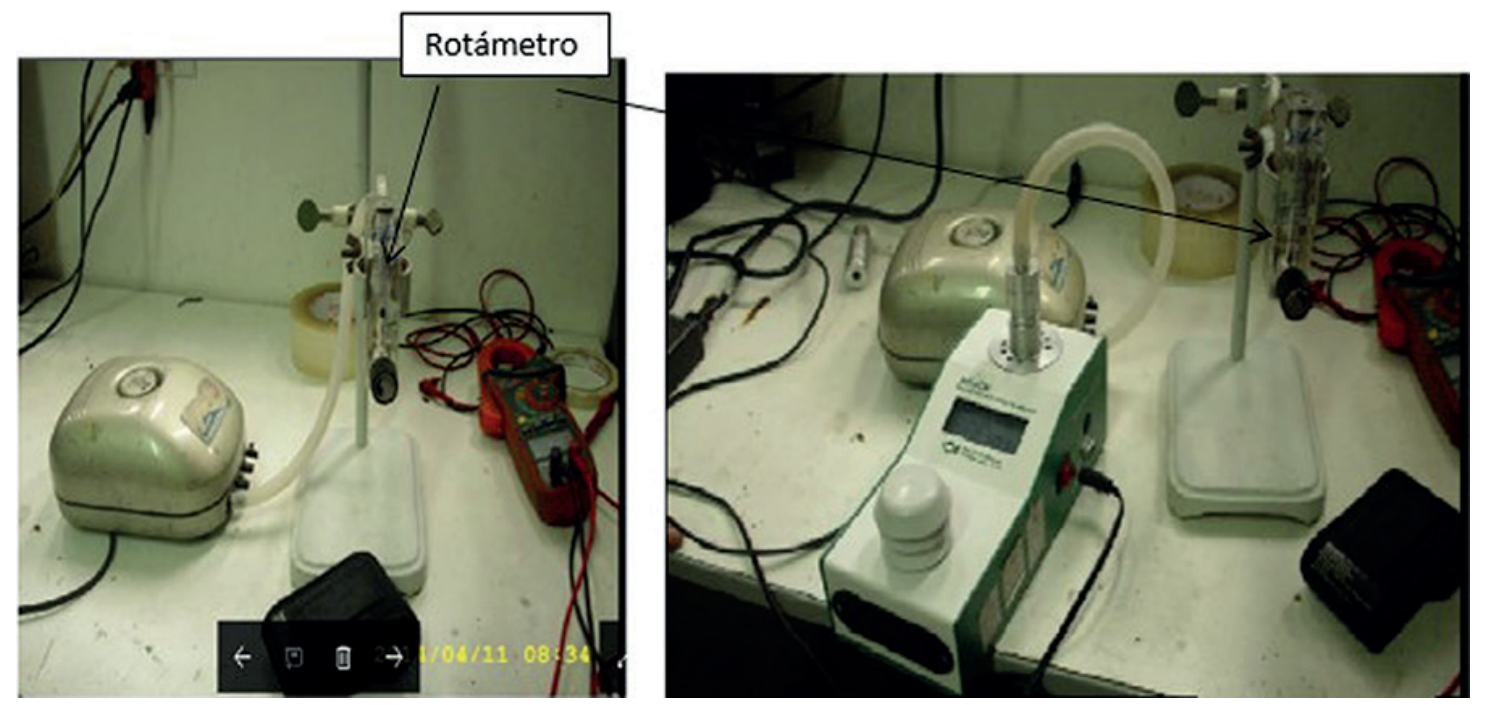

Figura 2. Calibrador secundario bgi calibrando rotámetro

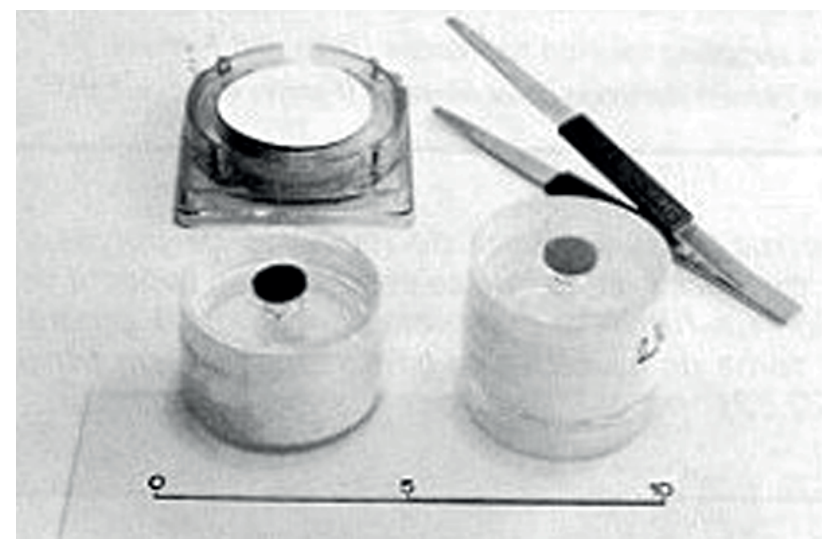

Figura 3. Portafiltro de tres cuerpos y filtro de celulosa 


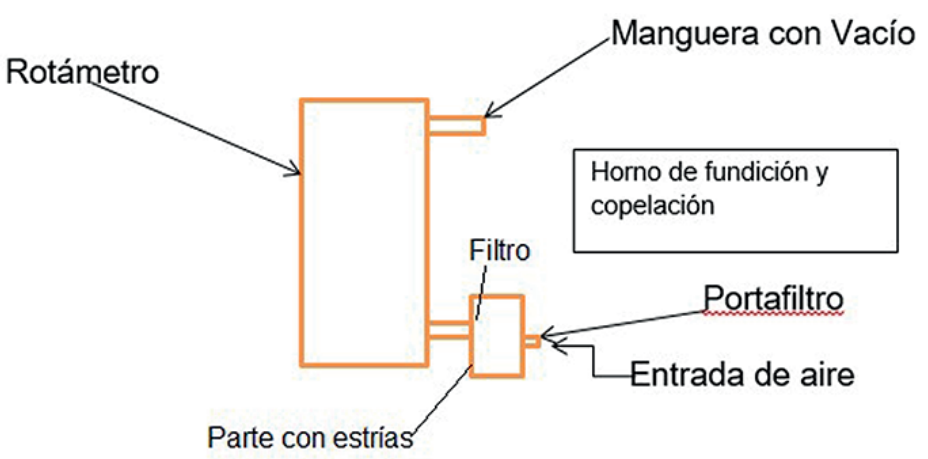

Figura 4. Armado del sistema de muestreo

fiolas de $10 \mathrm{ml}$. Se lavan los vasos con dos porciones de 2 $\mathrm{ml}$ calentando a $80^{\circ} \mathrm{C} 15-60 \mathrm{seg} . \mathrm{se}$ trasvasan los lavados a la fiola de $10 \mathrm{ml}$, se enfrían las fiolas, y se enrasan con agua des ionizada. Leer con curva de $\mathrm{Pb}$ al $10 \%$ de $\mathrm{HNO} 3$ con puntos entre 0-5 ppm.

Para el ataque de las muestras de sólido del suelo, se toma peso de muestra entre $0.25-0.7 \mathrm{~g}$ en vasos de $50 \mathrm{ml}$, se añade $20 \mathrm{ml}$ de ácido nítrico 1:1, se calienta la muestra a $110^{\circ} \mathrm{C}$ hasta $10 \mathrm{ml}$ aproximadamente, se concentra a sequedad a $80^{\circ} \mathrm{C}$; enfriar y añadir $5 \mathrm{ml}$ de agua y $1 \mathrm{ml} \mathrm{de}$ ácido nítrico concentrado, se calienta un minuto a $80^{\circ} \mathrm{C}$ y se trasvasa el líquido a fiolas de $10 \mathrm{ml}$.

Se lava el vaso dos veces con $2 \mathrm{ml}$ de agua desionizada calentando a $80^{\circ} \mathrm{C}(1 \mathrm{~min})$ y se trasvasan los lavados a la fiolas de $10 \mathrm{ml}$ hasta enrase. Si hubiera sólido remanente filtrar o centrifugar para separar el líquido en otros recipientes de $10 \mathrm{ml}$.

\subsection{Lectura de las muestras}

Material necesario.

- Espectrofotómetro de absorción atómica con lámpara de cátodo hueco de plomo.

- Fiolas de $100 \mathrm{ml}$ para curva de calibración y de $10 \mathrm{ml}$ para las muestras.

- $\quad$ Estándar de Plomo de 1000 ppm. Preparar curva de $0-5$ ppm al $10 \%$ de $\mathrm{HNO}_{3}$.

i. Se calibra inicialmente el Espectrofotómetro según protocolo del fabricante.

ii. Se preparan la curva de calibración de 0-10 ppm $\left(1 \% \mathrm{HNO}_{3}\right)$ usando curva racional nueva.

iii. Se leen las muestras a $217 \mathrm{~nm}$., Ancho slit $1 \mathrm{~nm}$. Corriente de lámpara $5 \mathrm{~mA}$ flama aire acetileno. Pasar un blanco entre muestras.

\section{RESULTADOS}

Se realizó el muestreo en tres laboratorios ,en los cuales se firmó carta de confidencialidad del nombre del laboratorio debido a las consecuencias que puedan originar los resultados obtenidos en las mediciones de plomo por ser de carácter punitivo, por este motivo a los laboratorios los denominamremos con las letras Laboratorios X ; A ; B.

\subsection{Resultados en el Laboratorio $X$}

No permitieron medir $\mathrm{Pb}$ en aire ambiental a pesar de firmar carta de compromiso de confidencialidad. En horas extras de trabajo muestreamos el suelo del área de ensayos al fuego (Figura 5).

Obsérvese que el cartucho con el filtro está solo dos cuerpos, para que el sólido se deposite en el filtro y que la salida de la manguera de la bomba va directo al orificio.

Los resultados según Tabla 1 dan valores muy altos en plomo (en \%).

\subsection{Resultados en el Laboratorio A}

En el laboratorio A (foto 4) ni siquiera hay horno de extracción y el horno tiene fugas al ambiente de trabajo.

Los resultados oscilaban en la copelación en el punto cerca de la fuga $P$ superior entre $2000-3900 \mu \mathrm{g} / \mathrm{m}^{3}$.para un muestreo de 1 hora (Figura 6).

\subsection{Resultado en el Laboratorio B}

Tiempos de monitoreo 1 hora para la fundición y 1 hora para la copelación .Al contrario de lo que se espera, la fundición dio valores más altos en la fundición que la copelación debido a que, la copelación se usó una buena velocidad de extracción, y en la fundición no se usa el extractor (Figura 7).

La copelación dio valor más alto de $30.21 \mu \mathrm{g} / \mathrm{m}^{3}$, en cambio la fundición el valor más alto de $213 \mu \mathrm{g} / \mathrm{m}^{3}$. (no usan extractor, y 2 hornos en uso, que usando extractor da valor entre $5-17 \mu \mathrm{g} / \mathrm{m}^{3}$ ) con 28 crisoles .

\section{DISCUSION}

Los ensayos al fuego de oro y plata generalmente son aproximadamnete 1 hora. La legislación internacional sobre contenido de plomo ocupacional esta basado generalmente para exposiciones de 8 horas. En el Perú se han copiado estos límites (Tabla 2). 

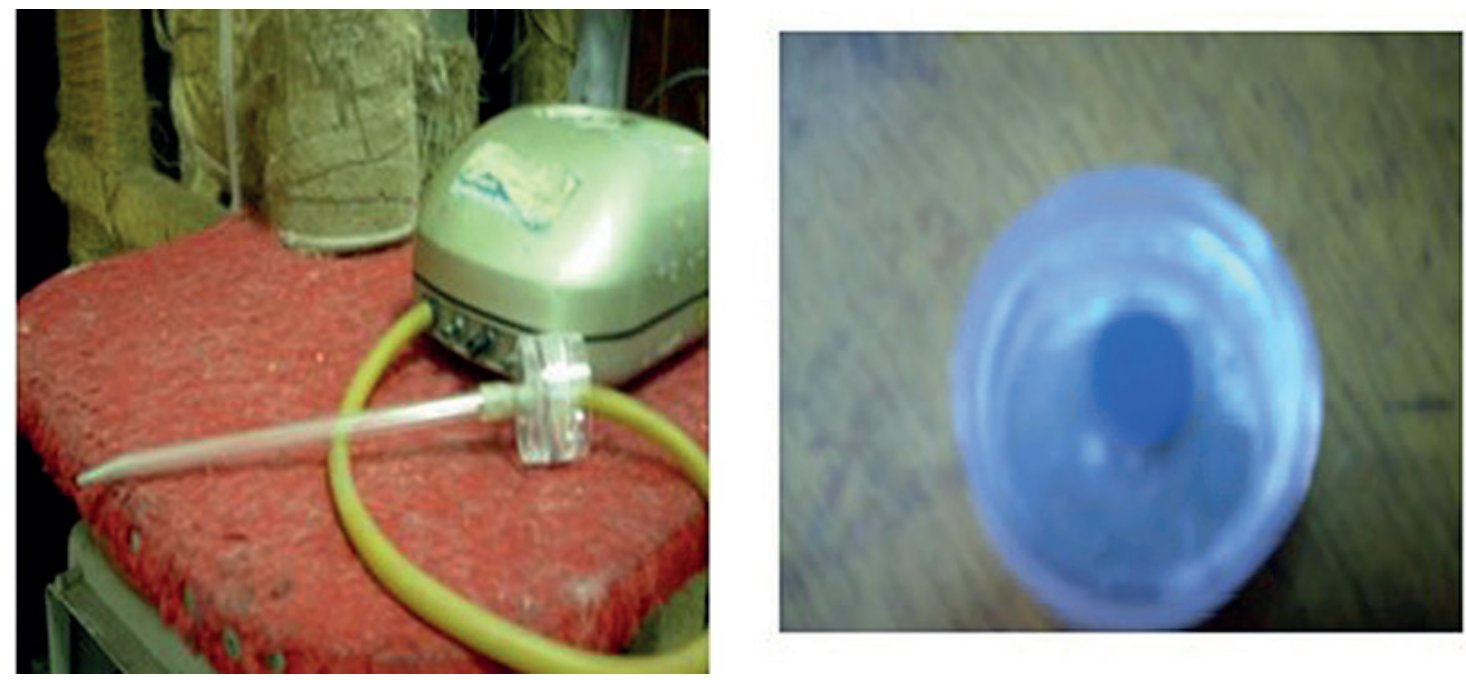

Figura 5. Equipo de muestreo del suelo del área de ensayos al fuego con la muestra de color oscuro

Tabla 1. Resultados Plomo en suelo laboratorio $X$

Plomo en el suelo Lab. X1

\begin{tabular}{|c|c|c|c|c|c|c|c|c|}
\hline Mtra & peso $\mathrm{g}$ & dil & 2da -3ra dil & Abs & C & ppm & $\%$ & Observaciones \\
\hline 1 & 0.25748 & a $10 \mathrm{ml}$ & $1->25-1->10$ & 0.0951 & 9.832 & 95463.7253 & 9.5463725 & Sólido de color oscuro a 2 m del horno \\
\hline 2 & 0.68952 & a $10 \mathrm{ml}$ & $1->25-1->10$ & 0.3613 & 43.54 & 157863.441 & 15.786344 & Sólido de color oscuro a 2 m del horno \\
\hline 3 & 0.49196 & a $10 \mathrm{ml}$ & $1->25-1->10$ & 0.2529 & 28.115 & 142872.388 & 14.287239 & Sólido de color oscuro a 2 m del horno \\
\hline 4 & 0.30526 & a $10 \mathrm{ml}$ & $1->25-1->10$ & 0.0998 & 10.334 & 84632.7721 & 8.4632772 & Sólido de color oscuro a 2 m del horno \\
\hline 5 & 0.31223 & a $10 \mathrm{ml}$ & $1->25-1->10$ & 0.20006 & 21.914 & 175463.601 & 17.54636 & Sólido de color oscuro a 2 m del horno \\
\hline 6 & 0.25597 & a $10 \mathrm{ml}$ & $1->25-1->10$ & 0.151 & 16.052 & 156776.185 & 15.677618 & Sólido de color oscuro a $1 \mathrm{~m}$ del horno \\
\hline 7 & 0.17446 & a $10 \mathrm{ml}$ & $1-->25-1->10$ & 0.0229 & 2.358 & 33789.9805 & 3.3789981 & Sólido amarillo(restos de copelas) 4 m \\
\hline 8 & 0.25416 & a $10 \mathrm{ml}$ & $1->25-1->10$ & 0.1023 & 10.714 & 105386.371 & 10.538637 & Sólido de color oscuro a 4 m del horno \\
\hline 9 & 0.25 & a $10 \mathrm{ml}$ & $1-->25-1->10$ & 0.1209 & 12.728 & 127280 & 12.728 & Sólido de color oscuro a $5 \mathrm{~m}$ del horno \\
\hline 10 & 0.25 & a $10 \mathrm{ml}$ & $1->25-1->10$ & 0.1187 & 12.48 & 124800 & 12.48 & Sólido de color oscuro a $6.3 \mathrm{~m}$ del horno \\
\hline 7 & 0.25 & a $10 \mathrm{ml}$ & $1->25-10>10$ & 0.0229 & 23.458 & 23458 & 2.3458 & Sólido de color oscuro a $4 \mathrm{~m}$ del horno $4 \mathrm{~m}$ \\
\hline
\end{tabular}

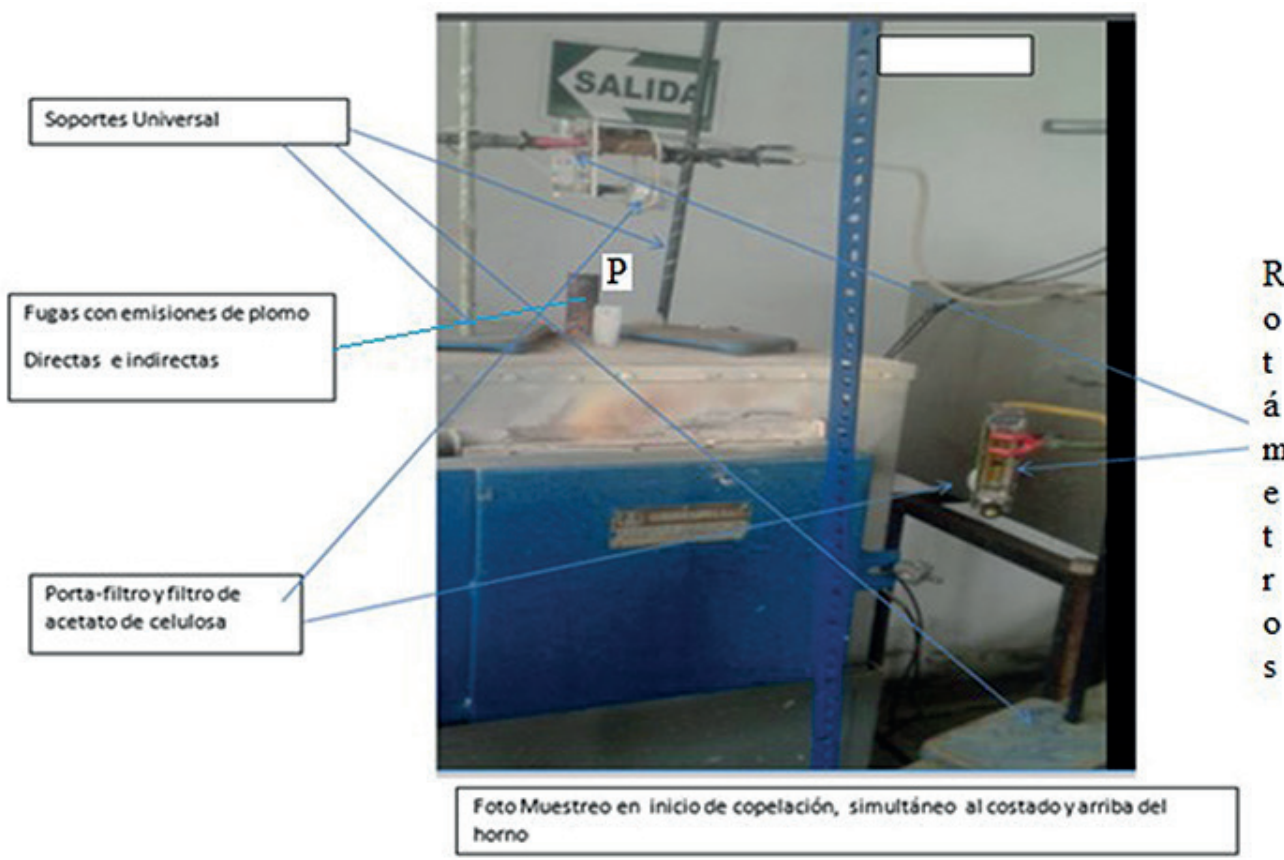

Figura 6. Foto muestreo laboratorio $A$ obsérvese la gran fuga $\mathrm{P}$ encima del horno 


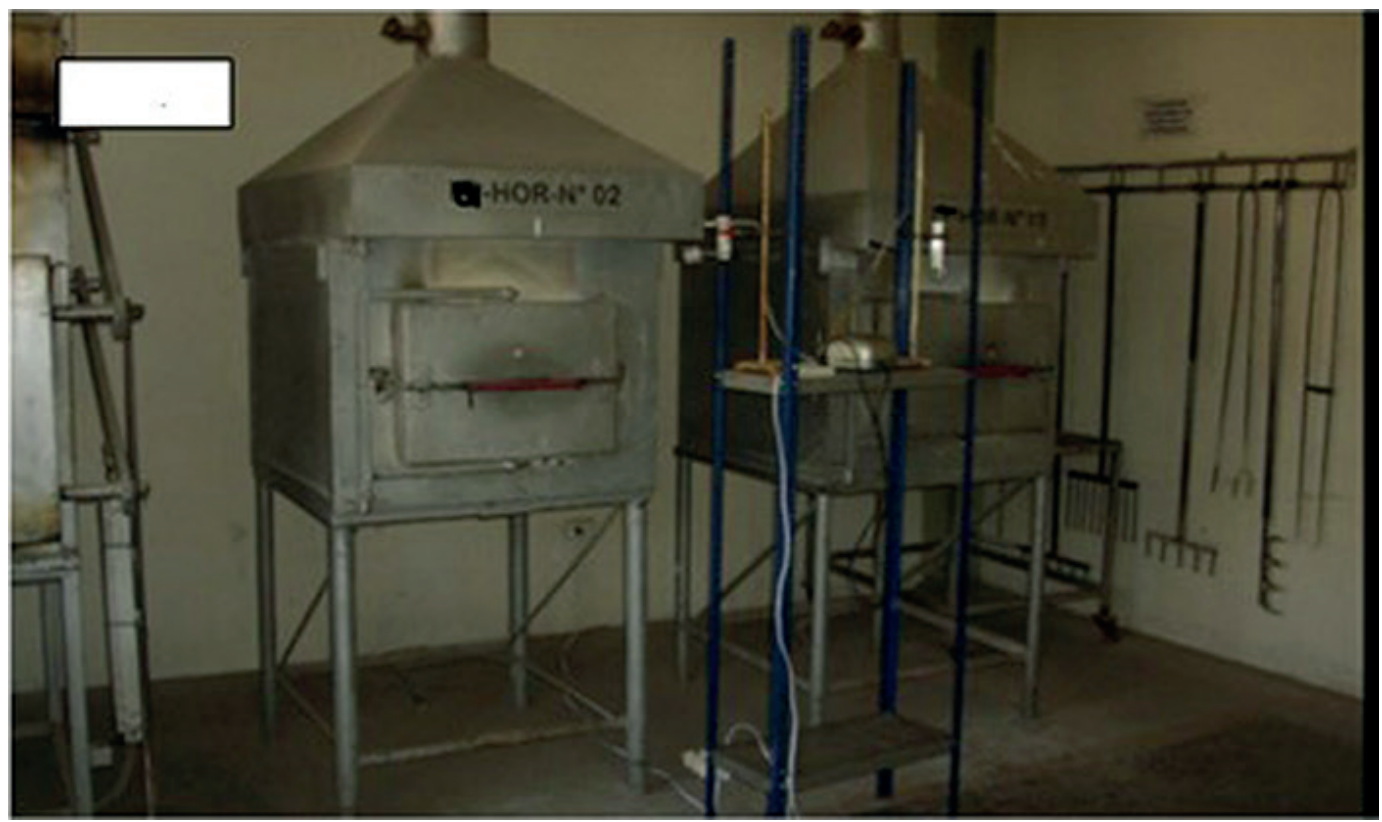

Figura 7. Monitoreo en Laboratorio B

Tabla 2. Valores límite de exposición plomo ocupacional promedio 8 horas (TWA)

valores de referencia en diferentes regiones y organismos internacionales

\begin{tabular}{lcccccc}
\hline & Pb.sangre $\mu \mathrm{g} \%$ & 70 & $70-80$ & 30 & 60 & 35 (hombre) \\
Valores límite de exposición & Pb-aire $\mu \mathrm{g} / \mathrm{m} 3$ & 150 & 150 & 50 & 50 & 10 (mujer en edad fértil) \\
\hline
\end{tabular}

ACGIH American Conferencia of Govermental Industrial Hygienists, NIOSH National Institute of Occupational Safety and Health, OMS Organización Mundial de la Salud, UE Unión Europea

El problema principal aquí es como garantizar que el muestreo brinde información en el monitoreo del aire ocupacional no sobrepase los límites establecidos.

Tenemos varios efectos a considerar entre los cuales se tienen: Tiempos de monitoreo, distancia del lugar de muestreo a la fuente, fugas del horno, número de hornos funcionado simultáneamente. Para el caso específico de ensayos al fuego que normalmente son aproximadamente 1 hora no hay legislación respecto al valor límite de corta duración.

Se tienen los límites de EUA promedio ponderado en el tiempo TWA para turno de 8 horas. Muchas empresas trabajan fundiendo y copelando menos de 8 horas. ¿Qué criterio se aplica? Por ejemplo supongamos que el valor de plomo en 1 hora es 60 y $40 \mu \mathrm{gPb} / \mathrm{m}^{3}$ para una empresa que trabaja 1 horas fundiendo y 1 hora copelando, si se sabe que el TWA según ACGIH es $50 \mu \mathrm{g} / \mathrm{m} 3$ para una jornada de trabajo de 8 horas. ¿Qué criterio usamos? Dejamos en 100 o lo dividimos entre 2; o entre 8 para no pasar el LMP de $50 \mu \mathrm{gPb} / \mathrm{m}^{3}$.

Se tiene otro problema que es la posición de la tomas de la muestra. Según INSHT español que sigue las recomendaciones de la NIOSH el muestreo se realiza colocando el filtro en el cuerpo del trabajador, y no se especifica dónde debe estar el trabajador.
Es decir que, el resultado es bajo si el trabajador si está lejos de la fuente y en oposición de la dirección del horno y alto si está cerca y en la dirección del horno.

Según DS 015-2015 SA el valor de TWA para 8 horas es $50 \mu \mathrm{g} / \mathrm{m}^{3}$ y define que el plomo evaluado se hace en el cuerpo del trabajador, no dice nada de la proximidad a la fuente.

En la tesis realizado por Argueta (2014), trabajando solo con 6 muestras para fundir y las muestra a 1-2 m en la fundición reportan valores de $\mathrm{Pb}$ menores a 0,08 ppm (se sabe que el $\mathrm{Pb}$ a valores bajos la inestabilidad puede llegar hasta $0,04 \mathrm{ppm}$ debido a su baja sensibilidad) que podrían ser $0,04 \mathrm{ppm}$.

En cambio las muestras que están más cerca a la puerta a menos de $1 \mathrm{~m}$ tienen valores 0,19 a 0,50 ppm es decir de 10-50 veces más que las más lejanas.

Los resultados para copelación varían entre 0,23$0.93 \mathrm{ppm}$ evidenciando que la copelación produce mayor cantidad de plomo al ambiente ocupacional. Según sus resultados obtuvo en fundición Fila 1: 0.047 ppm; Fila2: 0.050 ppm; Fila 3: 0.06 ppm.

Resultados que se obtuvo en las columnas en fundición: 
- $\quad$ Columna 1 ; P1 0.5 ; P2 0.19 ; P3 0.09 ; P4 0.18 ppm respectivamente

- $\quad$ Columna 2 ; P1 0.15; P2 0.07 ; P3 0.07 ; P4 0.13 ppm respectivamente

Para el proceso de copelación valores promedio de filas $0.376 \mathrm{ppm}$ y columnas 0.173 . Evidenciando la tendencia de que la copelación produce mayor emisión de plomo que la fundición.

Es evidente que el contenido de plomo va depender del punto de monitoreo, cuando más lejos menos plomo; la emisión de plomo se minimiza si el equipo tiene pocas fugas y una buena ventilación. A mi parecer que mejor criterio sería evaluar la contaminación de plomo cerca a la salida de la fuente en un lugar que salga resultados que se aproximen al valor de la emisión, por ejemplo en la puerta por la abertura del horno, y optimizando velocidad y flujo de ventilación de esta forma se minimiza la emisión de plomo.

Por otro lado, no hay procedimiento general de algunas buenas prácticas en fundición de ensayos al fuego en el Perú normalizadas, por ejemplo no comer entre los trabajos, limpieza del horno del plomo remanente, entre otros. Tampoco hay regulación sobre el sistema de ventilación que deben ser usados en los hornos, que según los trabajos de Hall et al (1998) para los ensayos al fuego las velocidades y flujos recomendados del extractor son (ver Tabla 3):

Es tarea de DIGESA de asumir este reto de corregir estas falencias. En los laboratorios visitados observamos las condiciones de trabajo y en algunos hemos hechos algunas mediciones cuyos resultados serán tema de tesis a futuro. Se monitorea usando filtros de acetato de celulosa, que son fácilmente degradables con ácido nítrico.

El caudal del flujo de aire del muestreo se mide con rotámetros calibrados. Finalmente, en el Perú no se exige a las empresas que venden respiradores de cartuchos, hacer el ensayo de fijación, ninguno de los tres laboratorios hasta ahora revisados, hacen ensayo de fijación de los respiradores de cartucho. Según el estudio de Spies et al (2011), el aspecto humano tiene mucha influencia en la eficiencia de los cartuchos de filtro en la capacidad de retención de polvos o humos en los filtros, por consiguiente es un factor en tomar en cuenta en la evaluación de la eficacia de los filtros para determinar su eficacia como protector respiratorio (Hall et al, 2011). En su estudio se demostró que al usar las mascarillas fabricadas en Estados unidos de Norteamérica en trabajadores africanos solo el $13.8 \%$ tuvieron ajuste adecuado. Sólo el 13,8\% $(n=4)$ de los participantes demostraron un ajuste exitoso (factor de ajuste $>100$ ) quienes tenían ancho de cara de $14-14.5 \mathrm{~cm}$ y longitud entre $11.4-11.9 \mathrm{~cm}$. (ver figura 8 y 9).

Tabla 3. Valores de velocidad del extractor

\begin{tabular}{lcccc} 
& Izq.abertura (fund.) & Centro (fund) & Derecha (fund.) & Copelación \\
\hline Veloc. $\mathrm{m} / \mathrm{s}$ & 6.8 & 3.76 & 2.44 & 1.37 \\
Flujo $\mathrm{m}^{3} \mathrm{~s}$ & 0.203 & 0.151 & 0.113 & 0.496 \\
\hline
\end{tabular}

${ }^{*}$ Se han convertido los valores del sistema inglés al americano del estudio original

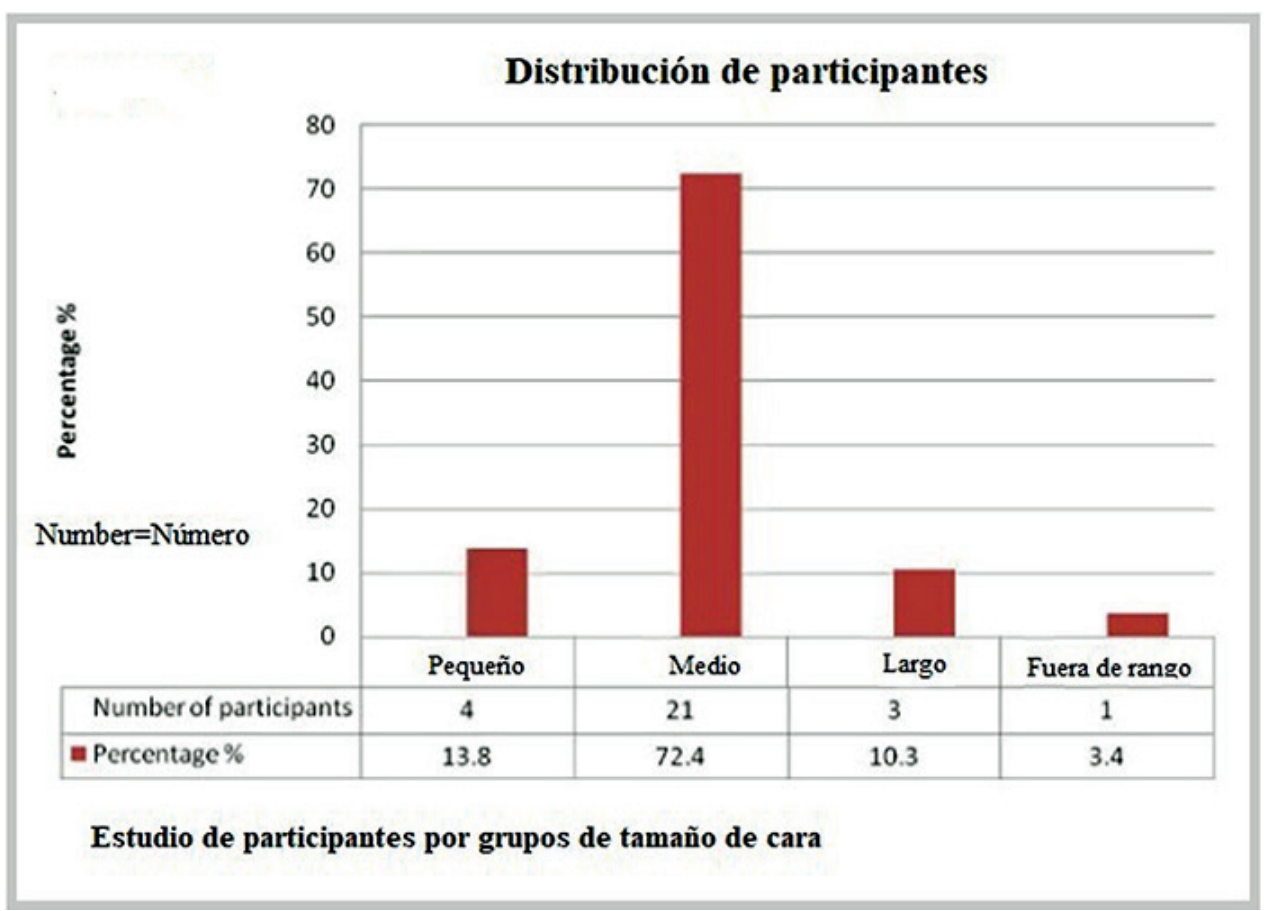

Figura 8. Estudio de participantes por grupos de tamaño de cara 


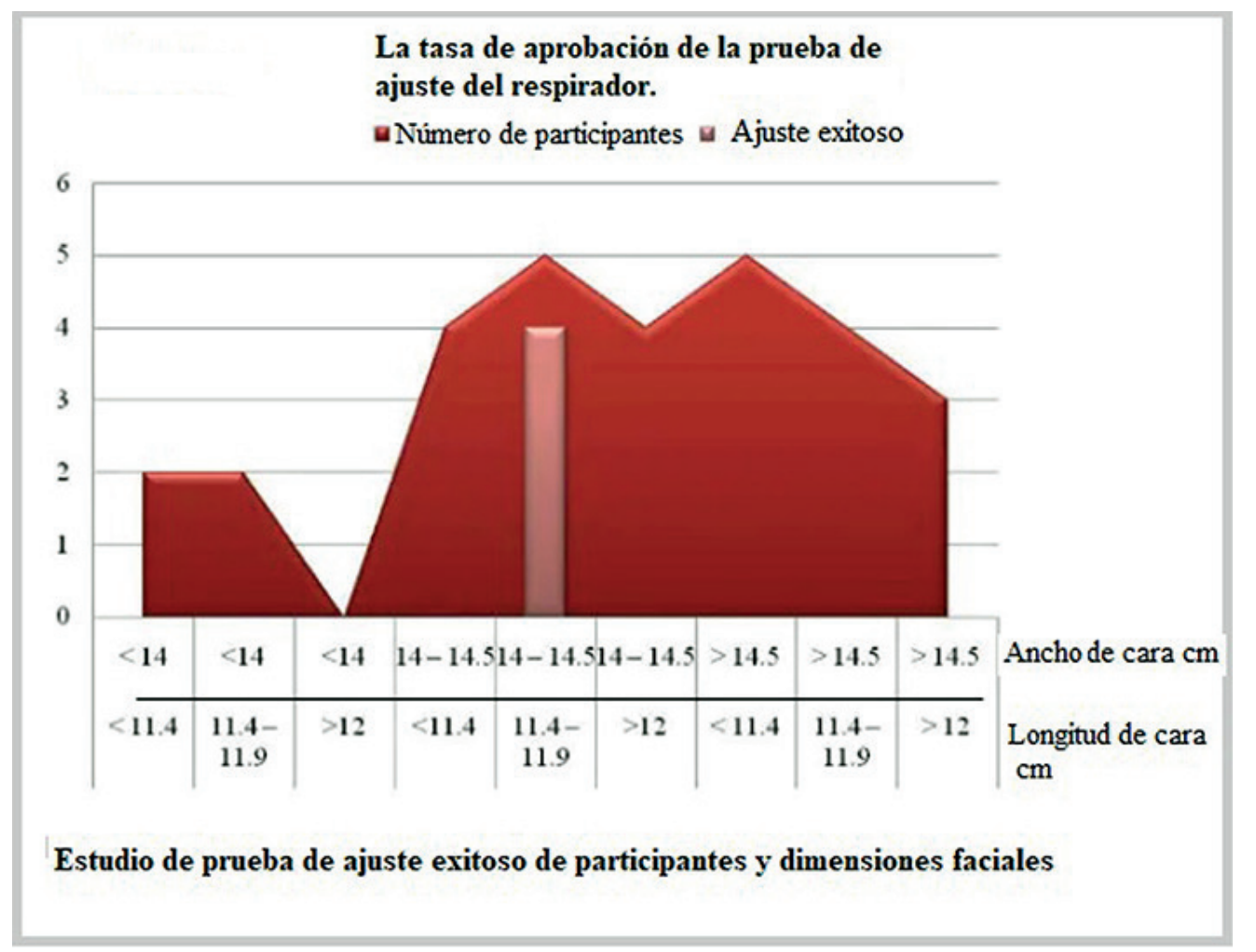

Figura 9. Estudio de prueba de ajuste exitoso de participantes y dimensiones faciales

\section{CONCLUSIONES}

Es evidente la falta de regulación en el Perú sobre las condiciones de trabajo en materia de seguridad y salud en el trabajo en los laboratorios de ensayos, no hay seguimiento sobre la salud de los trabajadores en dichas áreas, no hay procedimientos estándar de limpieza; solo se hace seguimiento del contenido de plomo ocupacional, cuando algún trabajador siente síntomas de daño por contaminación de plomo y se queja a SUNAFIL.

Las condiciones de trabajo en las áreas de ensayos al fuego no son controladas por algún ente fiscalizador, algunos laboratorios no tienen ni campana de extracción, y las que la tienen, su capacidad de extracción es muy baja como se ha corroborado experimentalmente, ni siquiera les hacen mantenimiento. En ningunos de estos laboratorios se hace los ensayos de fijación en los cartuchos de filtro que garantice un $95 \%$ de fijación de lo respiradores de dichos cartucho, principalmente porque no hay exigencia del estado de realizar dichos ensayos.

\section{AGRADECIMIENTOS}

Agradezco a mi asesor Mg. Ing. Fernando Anaya de la Facultad de Química e Ingeniería Química de la UNMSM por sus observaciones en mi trabajo, a la Profesora Nora Malca por sus observaciones y al Ing. Nabor Mucha por su apoyo. Al ingeniero Daniel Lovera de la FIGMMG por sus recomendaciones y a la Universidad Nacional Mayor de San Marcos.

\section{REFERENCIAS BIBLIOGRAFICAS}

Acaro, F.; Ccahuana, M.; Cahuana, T. (2014). “Intoxicación ocupacional por plomo en diversos grupos de Trabajadores del cercado de Ica" Revista Ágora Científica; 01(01):20-25. https://doi.org/10.21679/arc.v1i1.12

Argueta, E. (2014). Estudio sobre la verificación de condiciones ambientales seguras en el manejo de concentraciones altas de plomo en pruebas de ensayo ala fuego para la determinación de oro y plata (tesis de grado), Ingeniero Químico por la Universidad de San Carlos de Guatemala Facultad de Ingeniería Escuela de Ingeniería Química, Guatemala tesis/08/08 1412 Q.pdf

ATSDR-Agency for Toxic Substances and Disease Registry (2007). ToxFAQs ${ }^{\mathrm{TM}}$ sobre el plomo Recuperado de https:// www.atsdr.cdc.gov/es/toxfaqs/es_tfacts13.pdf

British Columbia (2016). A Guideline to Reducing Inorganic Lead Exposurein Fire Assay Laboratories. Office of the Chief Inspector of Mines. Ministry of Energy and Mines, pp. 17. Recuperado de https://www2.gov.bc.ca/assets/ gov/farming-natural-resources-and-industry/mineralexploration-mining/documents/health-and-safety/lead_ exposure_fire_assay_labs2016.pdf

Coffey, C.; Lawrence, R.; Campbell, D.; Zhuang, Z.; Calvert, C. \& Jensen, P. (2004). Fitting Characteristics of Eighteen N95 Filtering-Facepiece Respirators, Journal of Occupational and Environmental Hygiene, 1:4, 262-271. https://doi. org/10.1080/15459620490433799 
Dawn Tharr Column Editor (1991) Case Studies, Applied OccupationalandEnvironmentalHygiene, 6:4,252-254,DOI: DOI: https://doi.org/10.1080/1047322X.1991.10387872

Flame Atomic Absorption Spectrometry-Agilent (2017). Flame Atomic Absorption Spectrometry Analytical Methods, pp. 124. Recuperado de https://www.agilent.com/cs/library/ usermanuals/Public/0009.pdf

Hall, R.M.; Sheehy, J.W. \& Zimmer A.T. (1998) Engineering Controls in Mine Assay Laboratories, Applied Occupational and Environmental Hygiene, 13:9, 646-655, DOI: https:// doi.org/10.1080/1047322X.1998.10390133

Martí A. (1984). NTP 110. Toma de muestras de metales (polvos $y$ humos). Instituto de Seguridad e Higiene en el Trabajo. Ministerio de Trabajo y Asuntos Sociales de España. Recuperado de https://www.insst.es/InshtWeb/Contenidos/ Documentacion/FichasTecnicas/NTP/Ficheros/101a200/ ntp_110.pdf

Mérida, M. (2013). Evaluación del plomo presente en cada etapa del proceso de la determinación analítica de oro y plata en un laboratorio metalúrgico (tesis de grado) Ingeniero Químico. Universidad de San Carlos de Guatemala Facultad de Ingeniería Escuela de Ingeniería Química, Guatemala http://biblioteca.usac.edu.gt/tesis/08/08_1377_Q.pdf
Porter, K.; Cassandra, K.; Fearey D.; Castrodale, L.; Verbrugge, D. \& McLaughlin, J.(2015) Niveles elevados de plomo en sangre entre los trabajadores de ensayos de al fuego y sus niños en Alaska, 2010-2011. Public Health Rep. Sep-Oct; 130(5): 440-446. https://doi. org/10.1177/003335491513000506

Ramírez, A. (2008). Exposición a plomo en trabajadores de fábricas informales de baterías, An. Fac med. 69 (2):104-7 http://www.scielo.org.pe/pdf/afm/v69n2/a07v69n2.pdf

Spies, A., Wilson, K.S. \& Ferrie, R. (2011). Respirator fit of a medium mask on a group of South Africans: a crosssectional study. Environ Health 10, 17 (2011) https://doi. org/10.1186/1476-069X-10-17

Whelan, E.; Piacitelli, G.; Gerwel, B.; Schnorr, T.; Mueller, C.; Gittleman, J. \& Matte, T. (1997). Niveles elevados de plomo en la sangre en niños de los trabajadores de la construcción. Am. J. Public Health. Aug; 87 (8):1352-5. https://doi. org/10.2105/AJPH.87.8.1352 